\title{
Identificação racial e a produção da informação em saúde*
}

\author{
Andreia Beatriz Silva dos Santos \\ Thereza Christina Bahia Coelho ${ }^{2}$ \\ Edna Maria de Araújo $^{3}$
}

SANTOS, A.B.S.; COELHO, T.C.B.; ARAÚJO, E.M. Racial identity and the production of health information. Interface (Botucatu), v.17, n.45, p.341-55, abr./jun. 2013.

This study aims to analyze the production of information on the race/skin color of individuals submitted to autopsy at the Institute of Forensic Medicine (IFM) of Salvador/Bahia, in 2007. The evidence was obtained through interviews with forensic surgeons (coroners), autopsy assistants and the staff of the Corpse Release Department, as well as observations and documentary sources. The analysis revealed that the process of identifying race/skin color is neglectful, inaccurate and distorts the final information on death certificates. There was an indistinct classification of black and brown individuals as "pardos", which creates an informational "fog", while the death of whites coming to the IFM was "accidental." Murder, in turn, bears the mark of marginal violence, related to drugs, crime, which inscribes the dead in a horizon of culpability, almost justifying the violent death and the discrimination.

Keywords: Racial identification. Mortality information system. Racism. Race/color
Este estudo analisa a produção da informação sobre raça/cor da pele dos indivíduos submetidos à necrópsia no Instituto Médico Legal (IML) de Salvador, Bahia, no ano de 2007. As evidências foram obtidas em entrevistas com médicos legistas, auxiliares de necrópsia e funcionários do Setor de Liberação de Cadáveres, em observação e fontes documentais. A análise revelou que o processo de identificação da raça/cor da pele é omisso, impreciso e distorce a informação final da declaração de óbito. Houve uma indistinta classificação dos pretos e pardos como faiodermas, criando uma "névoa" informacional, enquanto a morte dos brancos que chegam ao IML foi "acidental". Já o homicídio traz a marca da violência marginal, relacionada com drogas, crime, com aquilo que inscreve o morto em um horizonte de culpabilidade, quase que justificando a morte violenta e a discriminação.

Palavras-chave: Identificação racial. Sistema de Informação sobre mortalidade (SIM). Racismo. Raça/cor.

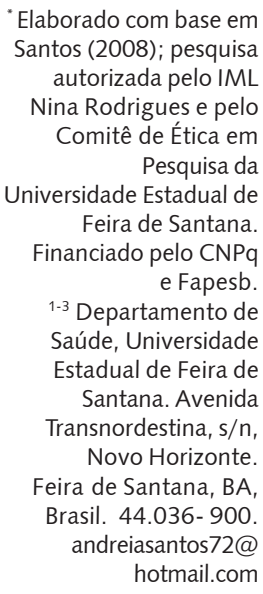

Elaborado com base em Santos (2008); pesquisa autorizada pelo IML Nina Rodrigues e pelo Comitê de Ética em Pesquisa da Universidade Estadual de Feira de Santana. Financiado pelo CNPq e Fapesb.

1-3 Departamento de Saúde, Universidade Estadual de Feira de Santana. Avenida Transnordestina, $\mathrm{s} / \mathrm{n}$ Novo Horizonte. Feira de Santana, BA Brasil. 44.036-900 andreiasantos72@ hotmail.com 
IDENTIFICAÇÃO RACIAL E A PRODUÇÃO DA INFORMAÇÃO ...

\section{Introdução}

A saúde de uma população sofre influência dos determinantes socioeconômicos e político-culturais, e o não-reconhecimento da sua singularidade racial a exclui e vulnerabiliza (Lopes, 2005). A exclusão decorrente da indiferenciação de grupos, como negros e índios, mantém as barreiras de acesso aos bens e serviços, fartamente documentadas na literatura especializada, sustentadas na negação de que elas, de fato, existam (Silva, 2006; Nascimento, 1989). No caso da população negra - quando comparada aos não negros -, a sociedade que exclui e nega o direito natural de pertencimento determina condições especiais de vulnerabilidade, como: menor acesso a água potável, menor nível de escolaridade e maior taxa de mortalidade infantil (Telles, 2007; Barbosa, 1998). Por isso, é necessário conhecer como se dá o padrão de adoecimento desta população, assim como os fatores associados às diferenças de morbimortalidade, para que se possa disponibilizar, adequadamente, a atenção à sua saúde (Dever, 1988).

A alta taxa de mortalidade por causas violentas incidente sobre os negros brasileiros e as evidências de distorção na base dos dados que compõem este vital indicador apontam para a necessidade de se estudar, em profundidade, como os dados que falam sobre a saúde dessa população são gerados e qual o sentido que assumem para os responsáveis pela sua produção: os profissionais de saúde (Araújo et al., 2009; Batista, 2005).

De fato, na busca de informações fidedignas sobre o óbito de negras e negros no Brasil, uma questão de extrema inquietação evidencia, no que diz respeito à identificação da raça/cor no exame de necrópsia, a impossibilidade da autodeclaração, prática adotada pelo Instituto Brasileiro de Geografia e Estatística (IBGE) e indicada pelo movimento negro brasileiro por remeter à identidade social do indivíduo (Cardoso, Santos, Coimbra, 2005).

Na Declaração de Óbito (DO), documento que alimenta o Sistema de Informação sobre Mortalidade (SIM), o quesito raça/cor (campo 17) disponibiliza as categorias: branca, preta, parda, amarela e indígena. O Ministério da Saúde (MS) recomenda que esse campo seja preenchido com um "x" para todos os tipos de óbitos, não havendo possibilidade da alternativa "ignorada". O médico é o responsável pelas informações contidas na DO e deve ainda verificar se todos os itens de identificação foram corretamente preenchidos (Brasil, 2001). Entretanto, distorções de informações da DO têm sido relatadas por alguns autores, a exemplo de Volochko (2005), tornando-se necessário evitar explicações definitivas e descontextualizadas, como alertam Chor e Lima (2005).

Na prática médico-legal, em especial, a omissão e, consequentemente, o sub-registro da raça/cor da pele, tornam-se mais problemáticos pelas implicações jurídicas que a morte violenta traz. Assim, como ocorre esta identificação e seu registro de fato?

Ainda que alguns autores prefiram o conceito "etnia", o termo "raça" tem sido adotado pelo Movimento Social Negro no Brasil. A categoria "negro" inclui "pretos" e "pardos" por se entender que, historicamente, os indivíduos que se autodeclaram pretos e pardos são aqueles que têm sido tratados discriminadamente, encontrando-se, em largas proporções, à margem do processo políticodecisório. Já o termo "etnia" está relacionado diretamente a uma dada população ou grupo, que apresenta certa homogeneidade cultural, ou seja, partilha história e origem, além de traços como: ancestralidade, território, valores, cultura e aparência física, entre outros (Ferreira, 2006).

No Brasil, qualquer pessoa, com base nas inúmeras classificações que circulam, tanto oriundas do senso comum quanto do conhecimento transmitido academicamente, reconhece um negro, um branco, um indígena. Cada um carrega uma construção da ideia de raça no seu imaginário (Azevedo, 1990). Por outro lado, a identidade racial branca agrega um conjunto de informações que remetem a privilégios objetivos ou simbólicos, benefícios concretos (branquitude), que direcionam o olhar do branco, evitando identificar o lugar que este grupo racial ocupa na história do país (Bento, 2002).

Em se tratando da população negra, o processo de sequestro de suas regiões de origem e dispersão por todo o litoral brasileiro forçou adaptações culturais, que preservaram os laços da origem em uma matriz cultural de base africana enquanto "[...] um instrumento de identidade coletiva" (Reis, 2003, p.310). Muitas e diversas etnias oriundas do continente africano que possuíam línguas e costumes distintos, como os bantos, os iorubás e os nagôs, modificaram suas especificidades de origem e foram 
agregados sob uma denominação mais ampla, pois os escravizados eram identificados por porto de embarque. Por exemplo, utilizava-se o termo iorubás para se referir a povos como: os oyó, ijexá, ketu, ijebu, egbá, ifé, oxogbô (Prandi, 2000).

Desse modo, o conceito de raça como uma construção social, que se opera por meio da racialização e hierarquização de grupos e pessoas, com base no reconhecimento de variações fenotípicas e históricas, mostra-se mais adequado aos objetivos deste estudo. A racialização é aqui entendida como ação política e ideológica que constrói uma suposta unidade biológica (Cashmore, 2000) e insere a categoria "raça" em um contexto de discriminação. Esta discriminação, quer encontre suporte na ignorância, quer no preconceito, faz com que determinados grupos racializados, a exemplo dos negros, sejam destituídos de direitos legalmente assegurados e não compartilhem com os não negros espaços de poder historicamente assentados e refratários à real participação.

Para Figueroa (2004), o uso da denominação "raça negra" possibilita a passagem de um atributo de prognóstico reservado - por conter em si um traço indicativo de uma marca histórica de opressão e discriminação - para um nível de "racialização positiva". Pretende, com isto, superar o quadro adoecedor e excludente, estruturalmente imposto e conjunturalmente atualizado. Assim, a autora define "raça" como categoria

[...] que foi histórica e culturalmente construída e que é constituída de pessoas que são, efetiva ou potencialmente, vítimas de desvantagens sociais por efeitos de preconceito e discriminação relativos à origem étnica ou às marcas visíveis de que são portadoras: a cor ou outras características físicas superficiais. (Figueroa, 2004, p.2)

Tanto para Figueroa (2004) quanto para Osório (2003), a racialização gera a pauperização, e não o contrário - argumento por muito tempo utilizado para explicar as diferenças sociorraciais no Brasil. No que diz respeito às desigualdades, pretos e pardos estão mais próximos em sua vulnerabilidade do que brancos e pardos.

A nomenclatura adotada para a identificação da raça/cor da pele, durante o exame de necrópsia nos serviços médico-legais, é baseada em caracteres fenotípicos e foi introduzida por Edgar Roquette-Pinto em 1933, levando em conta, sobretudo, a cor da pele e alguns dados biométricos, cujas denominações ele teria adaptado do grego: melanoderma (melanodermos) para pretos; leucoderma (leucodermos) para brancos; faioderma (phaiodermos) para pardos; xantoderma (xanthodermos) para amarelos (Ramos, 2003). O termo "eritroderma" foi acrescentado posteriormente para indígenas.

Já a DO, que será preenchida com base nos dados do Laudo de Necrópsia (LN), que, por sua vez, adota os termos de Roquette-Pinto, disponibiliza as mesmas opções que o Instituto Brasileiro de Geografia e Estatística (IBGE): branco, pardo, amarelo, indígena e preto. Haveria, em princípio, uma correspondência entre essas categorias que permitiria uma tradução não problemática das informações do LN, para a DO, mas, no cotidiano institucional, como se desenvolveria esse processo? Além disso, se, na prática médico-legal, a omissão torna-se mais problemática ainda pelas implicações jurídicas que a morte violenta traz, como se justifica o sub-registro da raça/cor da pele, informação crucial para a identificação das vítimas de morte violenta?

Este artigo tem por objetivo analisar o processo de identificação da raça/cor da pele no Instituto Médico Legal (IML) de Salvador, Bahia, no ano de 2007, levando-se em conta os determinantes históricos da formação social e cultural, no que tange às relações raciais no Brasil.

\section{Metodologia}

A estratégia adotada foi o estudo de caso do tipo descritivo analítico, que pode fornecer respostas sobre como os indivíduos desenvolvem relações consigo mesmos e com os grupos com os quais convivem e constroem sua realidade social, quer de forma conflitante, cooperativa ou indiferente, quer subordinada ou subordinante, instituída ou instituinte. 
Os sujeitos do estudo foram profissionais em atividade no Instituto Médico Legal Nina Rodrigues (IMLNR), de Salvador, Bahia, que estavam, direta ou indiretamente, ligados ao exame de necrópsia ao qual são submetidas as vítimas de mortes violentas: oito médicos legistas, três funcionários do setor de Liberação de Cadáveres (SLC) e dois auxiliares de necrópsia. Uma vez que a responsabilidade do preenchimento da DO, incluindo o quesito raça/cor, é do médico legista, este se constituiu no foco do estudo, inicialmente. Durante a pesquisa de campo, observou-se que outros sujeitos também participavam ativamente do processo de identificação dos corpos, sendo, portanto, incluídos no estudo.

A principal técnica de coleta utilizada foi a entrevista semiestruturada. Em seu roteiro, constaram: informações sobre a identificação, formação e trabalho, estrutura e organização do trabalho, processo de trabalho, preenchimento dos campos 49 (causa mortis) e 17 (raça/cor) da DO. As entrevistas foram realizadas no segundo semestre de 2007 e complementadas com dados da pesquisa documental (laudos de necrópsia e declarações de óbito) e da observação.

Para melhor compreender as mudanças de raça/cor da pele operadas no trânsito do cadáver pelos setores do IMLNR, procedeu-se, também, à coleta de três tipos de registros identificados - a Guia Policial (GP), o Boletim de Ocorrência $(B O)$ e a DO - de cem indivíduos submetidos à necrópsia em um período de 15 dias, enquanto se estava em campo entrevistando os profissionais, com a finalidade de se comparar e identificar possíveis mudanças na identificação racial. Sem pretensão de constituir amostra representativa do universo das DO do IMLNR, essas informações coletadas almejaram ratificar a hipótese construída, com base em evidências surgidas no próprio campo, de que os corpos "clareavam" ao longo do trajeto.

A análise dos dados foi realizada tendo como referência a análise de conteúdo, com inspiração em Minayo (1999), buscando a compreensão das respostas e dos argumentos apresentados pelos entrevistados, de maneira que fossem abarcados os conteúdos, manifestos ou latentes, presentes nas falas, gravadas e transformadas em texto via transcrição. Os textos das entrevistas, ao serem triangulados com a observação da prática, com o material da análise documental e com os dados quantitativos, ganharam novos sentidos e uma aproximação privilegiada dos eventos investigados.

\section{Raça/cor da pele: uma variável de pertencimento e discriminação do "ser negro"}

A discussão sobre o preenchimento do campo 17 da DO foi marcada pela dificuldade que envolve o processo. Os entrevistados buscaram se justificar, ora sob a forma de um argumento racional, ora por meio de um afeto suscitado. A complexidade da tarefa foi desvelando-se, gradualmente, na fala dos entrevistados e alcançando o status de algo mais.

Em um primeiro momento, a identificação apresentou-se como uma medida simples e objetiva, pueril; afinal de contas, só diz respeito a um processo mecânico, manual, "é só preencher", como de "praxe". Uma ação quase insignificante. Partia-se do entendimento de que a determinação da raça/cor deveria ocorrer, pelo menos teoricamente, durante a realização do LN, e que, depois desta determinação, uma tradução seria operada da classificação médico-legal para a classificação da DO. Entretanto, ao se questionarem os técnicos envolvidos sobre o modus operandi dessa tradução e qual a função das informações preexistentes na determinação da raça ou cor da pele, as dificuldades apresentaram-se de modo intenso e variado.

Observou-se, durante o acompanhamento do procedimento de liberação de cadáveres, que os reclamantes do corpo eram questionados pelo profissional do setor sobre o atributo do campo 17, deixando a resposta aberta, da seguinte forma: "qual a cor da pele do cadáver?" ou "qual a cor da pele do morto?" Apenas quando identificava alguma dificuldade na determinação operada pelo familiar ou reclamante, ele disponibilizava as opções que constam na DO.

Percebeu-se que esta prática trazia constrangimento para os funcionários, pois, algumas vezes, os questionados manifestavam dúvidas ou respondiam com outras alternativas, como: "moreninhos", "moreno claro", "mulato". Esse deslocamento obrigava o funcionário a intervir, causando mal-estar quando a pessoa não fornecia um dado preciso, que pudesse ser "encaixado" nas alternativas existentes, do mesmo modo que o fornecimento de uma informação discrepante da percepção do técnico causava inquietação: 


\begin{abstract}
“[...] porque aqui tem o item 17, que diz assim: raça e cor. Aí tem o quadradinho. Aí tem escrito branca, preta, amarela, parda, indígena. Na hora em que eu estou fazendo o preenchimento da declaração de óbito, eu pergunto à família qual é a cor da pele do falecido. Muitas vezes, a pessoa diz assim: 'ah, é branca'. Aí eu coloco branca. Às vezes, 'é da minha cor'. Às vezes, a pessoa é escura, é da minha cor, aí eu digo: 'Senhor, eu estou perguntando ao senhor qual é a cor, porque não sou eu que vou dizer a cor da pele da pessoa'. Eu acho que... Não sei se é vergonha de dizer que a cor é preta. Aí diz: "É da minha, da minha cor". Aí, muitas vezes, diz 'parda'. Eu não posso botar parda se a cor é escura. Aí eu vou, coloco 'preta'. Na hora, eu digo: 'Oh senhor, eu perguntei, o senhor disse que era 'da minha cor'. Aí eu olhei e vi que a cor do senhor era escura, e aqui tem que ser 'negra'. Mas, infelizmente, no formulário tem preta, certo? Porque aí pode ter discriminação, né? Às vezes, a pessoa fica assim, meio chateada, mas eu não posso fazer nada, né? A declaração de óbito não foi eu que mandei fazer com a cor da pessoa, né? Porque se eu fosse fazer, eu não botaria preta, botaria negra". (Ent6/T/L)
\end{abstract}

Esse depoimento suscita um questionamento: Como se dá esse procedimento, que é de responsabilidade do legista na prática, e que termina sendo feito pelo funcionário do atendimento do Setor de Liberação de Cadáveres (SLC), após uma "negociação" com o reclamante?

Vários documentos concorrem para a informação final acerca da raça/cor do corpo, durante o trajeto percorrido pelo cadáver desde fora do IMLNR - tendo como evento deflagrador o óbito - até a chegada ao SLC da instituição:

a) Solicitação de Encaminhamento de Remoção para o IML (SER-IML) - quando o atendimento médico é feito em hospitais e existe dúvida se o óbito ocorreu por causa violenta. Esse documento apresenta, como alternativa para a identificação da raça/cor da pele, o espaço "cor da pele". Quem preenche é o médico que constatou o óbito;

b) Boletim de Ocorrência (BO) - quando a polícia é comunicada da ocorrência de morte por causa violenta, é gerado um boletim de ocorrência policial. É um formulário digital com oito opções para identificação da raça/cor da pele: preto, branco, pardo, amarela, indígena, eritroderma, xantoderma, ignorado. Quem preenche é o plantonista da Delegacia de Polícia;

c) Guia Policial (GP) - uma vez feito o BO, é emitido este documento, que segue com o corpo e apresenta as seguintes opções: branca, parda, amarela, vermelha, negra, ignorada. Quem preenche é o plantonista da delegacia de Polícia;

d) Laudo de Necrópsia (LN) - apresenta uma lacuna para a informação da cor da pele, não fornecendo opções fechadas. É preenchido pelo legista. Esse laudo dará origem ao Laudo Médico Legal (LML), documento final que será encaminhado à Secretaria de Segurança Pública;

e) Declaração de Óbito (DO) - contém informações sobre a raça/cor do indivíduo morto, oferecendo as opções raça/cor da pele: branca, preta, parda, indígena, amarela. É preenchida por técnico, no setor de Liberação de Cadáveres do IMLNR, com base no LN ou na declaração do reclamante do corpo.

Ao final do trajeto, permanecem a GP e o LML, juntamente com a Declaração de Óbito, que serão arquivados no setor de estatística do IMLNR. A Figura 1 esquematiza os momentos e instrumentos de registro da raça-cor da pele no interior da instituição pesquisada.

Percebe-se, na Figura 1, que, embora constem informações acerca da raça/cor da pele das vítimas que serão submetidas à necrópsia no IMLNR nos vários documentos, a forma como estão dispostas as categorias da identidade racial diferem entre si; elas podem variar no trânsito desde o óbito, causando discrepâncias no que tange à raça/cor da pele do indivíduo.

Essas diferenças ficam melhor percebidas quando se sai do âmbito particular dos documentos e se analisam as proporções em quantitativos maiores que fornecem uma visão de conjunto. Comparando-se os três tipos de registro de cem indivíduos submetidos à necropsia, 32\% tiveram sua identidade racial "parda" definida no início (BO). Após a necrópsia (LN), este quantitativo mais que duplicou, passando para $72 \%$ de "pardos" (faiodermas), caindo, por fim, para $68 \%$ na Declaração de Óbito (Figura 2). 
IDENTIFICAÇÃO RACIAL E A PRODUÇÃO DA INFORMAÇÃO ...

Figura 1. Trajetória institucional do corpo morto e documentos onde consta a raça/cor da pele, Salvador - Ba, 2007.

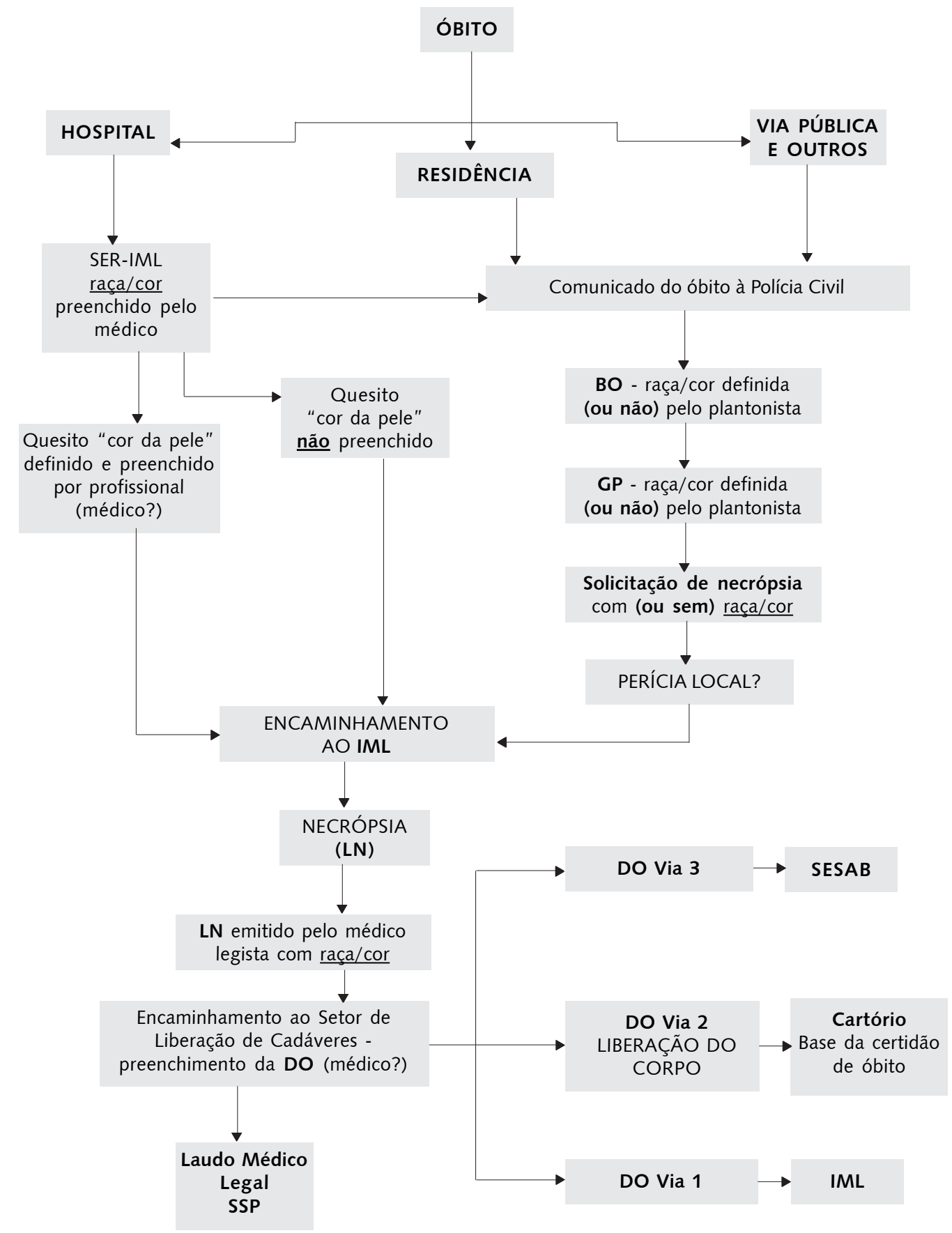

Fonte: IML Nina Rodrigues. Elaborado pelos autores. 
Figura 2. Diferenças nos registros da raça/cor da pele entre documentos emitidos durante o trajeto do corpo morto, em cem óbitos, por causas violentas, nas duas primeiras semanas de maio do ano de 2007, no IML de Salvador/Bahia.

Guia policial

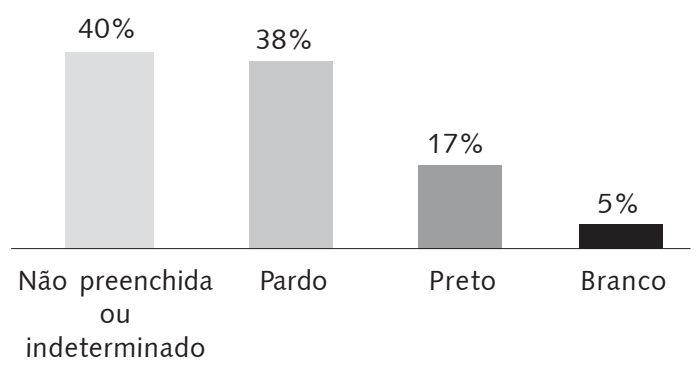

Laudos de necrópsia do IML-SSA

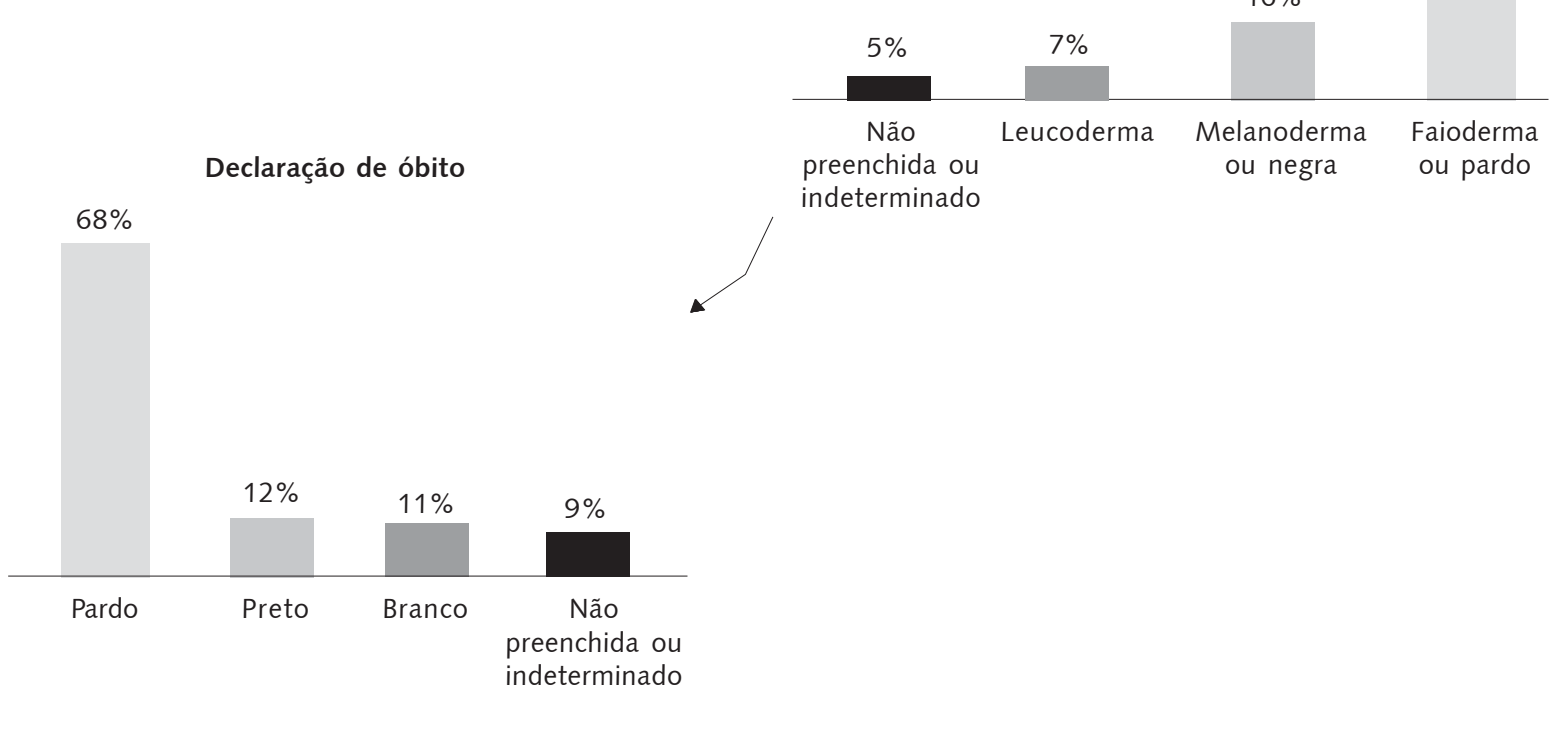

Observando-se a população de Salvador que, em 2007, apresentava 54\% de pardos, $28 \%$ de pretos e 17\% de brancos, em um total de 3,647 milhões de habitantes (IBGE, 2012), fica evidente que a proporção de pessoas pardas que morrem por causas externas está acima da sua representação na população de Salvador, e a identidade racial dessas pessoas sofre alterações ao longo do processo que envolve o exame necroscópico.

O BO representa, seguramente, a forma como a sociedade - e, em especial, a polícia - identifica a raça-cor dos indivíduos mortos violentamente. Observa-se, então, que mais indivíduos são identificados como "pretos", embora $40 \%$ da informação sejam negligenciados. Deste modo, a definição da raça/cor da pele, ao contrário do que se esperava, ficava rotineiramente a cargo do familiar ou reclamante do corpo. Ainda que o correto preenchimento e a fidedignidade dos dados constantes na DO sejam da responsabilidade do médico que realiza o exame (Brasil, 2001), isto não ocorre como rotina.

Constataram-se, ainda, divergências nas falas dos entrevistados sobre a possibilidade de a raça/cor da pele atribuída pelo responsável pela retirada do cadáver concordar ou não com a "realidade" observada pelo técnico, que terminava, em muitos casos, induzindo a resposta:

"A declaração que vem pra aqui é a gente que preenche. Como o médico não coloca a cor, a gente que procura saber da família [...] Se ele for negro, como é que eu posso colocar 
branco? Ah, você é da família está dizendo que ele é branco, então eu tenho que colocar branco. A família está dizendo é branco, tem que botar branco". (Ent 4/T/L)

Este comportamento ambíguo traduz uma indecisão entre a legitimidade "política" fornecida pela autodeclaração e a "verdade técnica" que o profissional tenta, certamente, preservar. Entretanto, dado que a realização das entrevistas buscou não apenas identificar concepções, percepções, mas, também, abrir um espaço de reflexão e interação entre entrevistador-entrevistado, como indivíduos competentes para argumentar e se entender, alguns profissionais, mesmo referindo o caráter "subjetivo" do ato de decidir sobre a raça/cor, questionaram-se sobre qual o fundamento mais adequado ou válido, aquilo que melhor definiria a realidade observada.

No processo de problematização forjado pela investigação, uma vez admitida a impossibilidade de a definição da raça/cor configurar-se somente enquanto processo objetivo, os entrevistados remetiam à "subjetividade", como obstáculo que demandaria uma necessidade de orientação e "educação". Ou seja, educar e orientar as pessoas, para que o processo de classificação seja fidedigno e elas saibam e reconheçam "quem" são. A questão é: quem deve dizer quem "eles" são?

O processo de definição de si e do outro, que leve em conta questões mais próximas do significado da raça/cor da pele para cada um, mas que gera repercussões para muitos outros, necessitaria ganhar espaços mais abertos a uma abordagem sem tabus, sem mitos. Como só o outro pode dizer quem é o indivíduo? É preciso que se permita uma subjetividade orientada em vida, e o seu reconhecimento objetivo em morte. Entretanto, parecem ser grandes os obstáculos percebidos justamente por médicos que deixaram de contribuir com a informação que interessa, especialmente, à população negra: “Um sistema melhor de classificação. Infelizmente, vai ter que ter um critério subjetivo nesses dados, porque ninguém vai dar" (Ent3/M).

Curiosamente, certo auxiliar de necrópsia ratificou as inúmeras pesquisas sociodemográficas sobre esse tema no Brasil, dentre elas a de Azevedo (1990), que afirmam que qualquer um sabe nomear um negro, um pardo ou branco, seja usando a terminologia do saber "científico", seja a do senso comum:

\footnotetext{
"Tem que ter sua identificação, tem que ter seu respeito. Seja em vida e morte, tá me entendendo? E aqui, então, no IML... Eu acredito em que todos os IML do mundo acontece, claro, né? Essa preocupação de descrever aquela coisa que está vendo ali, tá me entendendo? A gente não vai ver assim um negro da nossa raça e dizer: não, ele é um moreno, ele é um branco, tá entendendo? [...] Não, sabendo que descreveu uma coisa que não tinha nada a ver. Então, para isso, nós temos uma visão profissional, que temos que escrever tudo, e essa preocupação nossa é pra que sempre melhore a qualidade do trabalho da gente". (Ent7/T/A)
}

Aqui se chega a um momento crucial. Tendo em vista o discutido e observado, como se constitui a produção dos dados? A que se devem a dificuldade, a complexidade e a banalização da informação?

A despeito de ter como marcador principal a cor da pele, outras informações, como a característica do cabelo, o formato do nariz e dos lábios, bem como a cor da gengiva, funcionam como marcadores raciais e contribuem para formar uma identidade. Informações, como ângulo facial e protusão da mandíbula, contam, em caso de dúvidas. Chama a atenção o fato de os legistas, embora haja dúvidas do ponto de vista das características físicas, não lançarem mão de outros caracteres que tipifiquem o indivíduo.

Ainda que as características da população negra sejam reconhecidas por grande parte dos entrevistados, é consenso que a identificação como faioderma possibilita menor margem de erro. Isto porque identificar uma vítima de morte por causas violentas, como faioderma, permite que o identificado transite, simbolicamente, do branco ao negro, passando por todas as nuances possíveis, ainda que seja "apontado" como melanoderma.

Entenda-se que desta possibilidade de trânsito exclui-se o entendimento do pardo e similares como leucoderma. Na verdade, o faioderma refere-se ao não branco. O que resulta, na prática, de uma população bicolor: brancos e não brancos. O mito das três raças dissolve, na pardacidade, a quase totalidade dos cadáveres do IMLNR, porque os leucodermas são, ali, pouco frequentes. 
As falas também remetem a um dado político concreto, qual seja, a importância de agregar pardos e pretos na constituição da raça negra. Compreendendo-se que a categoria "negro" inclui os dois grupos, pois estes são aqueles que têm sido tratados discriminadamente, e se encontram à margem do processo político-decisório, por que não assumir a realidade, nua e crua, como ela é (Figueroa, 2004; Osório, 2003)?

No processo de identificação que ocorre no IMLNR, isto se mostrou extremamente peculiar. Entre pardos e pretos, todos parecem ser iguais. Durante a observação da prática, não foi percebida qualquer dúvida quanto à identificação dos leucodermas; ou eram faiodermas (não brancos), ou leucodermas (brancos).

Se a definição, efetivamente, leva em conta a informação fornecida pelo reclamante, seria esta uma alternativa legítima, como no processo de autodeclaração adotado pelo IBGE, dada a dificuldade que envolve a identificação racial (Cardoso, Santos, Coimbra Jr., 2005)? Este critério utilizado pelo plantonista do IMLNR, embora não seja o oficial, revela, na prática, uma medida que possibilita a relação com o pertencimento, ainda que exista uma mediação, às vezes pouco elucidada ou pouco orientada.

Desse modo, admite-se que o ato de definição do atributo raça/cor do morto está, sim, carregado de subjetividade, e, desse modo, por todos os valores que a construção da imagem de ser negro carrega. Não são utilizados critérios técnicos específicos ou procedimentos padronizados, mas critérios subjetivos - com base em experiências individuais e coletivas.

A indefinição não pode ser assumida, pois a DO não apresenta o item "indeterminado" ou "ignorado", mas esta possibilidade emerge repetidamente como uma alternativa nas falas e nos registros. O que remete ao SIM e à presença de óbitos de raça/cor "ignorada", ainda que o campo 17 não apresente esta alternativa. Por que isto ocorre?

\section{"Irrelevância" da raça/cor da pele}

Ao refletirem sobre o tema, os entrevistados expressaram sentimentos de espanto ou curiosidade em relação, não à existência do quesito, mas à importância desta informação. A maioria dos profissionais referiu não perceber nenhuma conotação racial no fato de os "afrodescendentes" morrerem mais. Admitir a realidade não é racismo.

Não é relevante declarar a cor do morto, porque já "se sabe de antemão" que "os pretos morrem mais", e morrem mais porque são pobres. São negros e pobres, mas, na opinião dos profissionais, só estavam lá porque eram pobres. A raça ou cor passa como algo acidental. Embora acidental seja a presença de brancos no IMLNR.

Entretanto, referem-se exatamente àquele grupo - negros - para se reportar à sua condição econômica, realizando a verdadeira identificação racial que parece tão complexa, tão difícil de tratar e, até mesmo, falar. Por tal motivo, esta forma de negação do outro como identidade diferente, mas positiva, pode ser considerada racismo. Todavia, se a desigualdade é "naturalizada" e o racismo é "oculto" ou "cordial", como ele opera ideologicamente no âmbito das práticas profissionais de saúde?

Uma das formas identificadas pelo estudo deu-se pela negação da importância da cor na identificação dos corpos, exceção feita àqueles com identidade social ignorada. Assim, um dos profissionais médicos defendeu uma suposta "inutilidade" e "irrelevância" da identificação racial no momento em que reconhecia que era por mera formalidade que o fazia, tendência observada entre outros membros da equipe técnica:

\footnotetext{
“Normalmente, seria de praxe que preencha, entendeu? Aí, só é colocar branca, parda, preta, amarela e indeterminado. Isso já vem na ficha daqui, que eu também acho extremamente simplista. Eu acho que, para o cadáver ignorado, deveria ter, pelo menos, outros critérios, entendeu? Acho importante porque é ignorado, mas, a nível estatístico, a nível de alguma coisa, honestamente, eu não vejo nenhuma importância, muito embora toda e qualquer pesquisa que a gente faça na área de medicina legal, a gente coloca pardo etc., Mestiço, parará, parará, se você quiser... Honestamente, eu não vejo nenhuma
} 
importância, porque, no nosso meio, é de se esperar que a maior parte dos homicídios e das mortes violentas seja de afrodescendentes [...]. Ainda é a parte da população menos favorecida, por questões históricas. Então, é de se esperar [...]. Então, honestamente, eu não percebo nenhuma correlação... nenhuma conotação racial. Eu acho apenas social e econômica, demográfica mesmo". (Ent3/M)

A contradição expressa nesse trecho da entrevista representa bem o problema. A determinação da cor é um processo "formal", "normativo", que se faz por obrigação e sem convicção, por ser algo tão subjetivo, tão ao sabor do gosto pessoal, que o que se deveria fazer, na opinião desse profissional, seria tirar "a foto da pessoa e deixar em anexo, cada um tira as suas consequências". Pois não existe nenhuma utilidade em se saber a cor de alguém em um "país como o nosso", ou seja, miscigenado. Todavia, se é um país mestiço e sem cor, como o mesmo profissional sabe que os negros são mais desfavorecidos social e economicamente?

Não seria esta imagem de país miscigenado acionada para promover a fuga do debate sobre as desigualdades entre negros e brancos, conforme tem mostrado fartamente a literatura crítica? 0 argumento leva à crença de que as várias possibilidades de tonalidades de cor invalidam o debate racial no país. Trata-se de um entendimento de que o país que preserva a herança do mito da democracia racial padece apenas das diferenças de classes. Frente a isso, perde relevância o fato de que morram mais pretos em virtude da violência.

\footnotetext{
"Porque, antropologicamente, você não consegue características caucasianas, nem puramente negroides. Você encontra sempre um meio termo. É pela própria característica nossa de miscigenação. E aí, você pega um livro estrangeiro... Isso é muito fácil de fazer, extremamente fácil, não há a menor dúvida de identificar [...]". (Ent8/M)
}

Com efeito, a percepção desse profissional conecta-se à do senso comum presente na sociedade brasileira acerca das relações raciais, que nega o debate sobre a existência do racismo, recusando-se, assim, a aceitar a existência de desigualdades dele resultantes. Uma vez que se trata de um tema que não importa ser discutido, para que, então, identificar, se o que será encontrado é o que já se sabe? O que isto mudaria? Para quem mudaria?

Pereira (1995) afirma que os dados produzidos pelo SIM abastecem uma base mantida e atualizada periodicamente pelo Estado, possibilitando, por meio de estatísticas, a realização de um diagnóstico de saúde que auxilie a tomada de decisão na gestão. Alguns entrevistados não pareceram reconhecer a relevância e utilidade dos próprios dados que geram.
“Realmente, vou ser sincero, não sou eu que preencho esse campo. A gente está muito mais preocupada em fazer o laudo, e pouco, assim... Mas lógico que a causa mortis é a preocupação também". (Ent11/M)

Em divergência, outros reconheceram essa importância, sobretudo em referência à construção de políticas públicas e, ainda, identificam a discriminação como um empecilho para a identificação racial do periciado.
"É uma questão extremamente delicada. Em termos de políticas públicas, você tem que pensar nisso sempre. No ponto de vista pessoal, não tem muito como resolver, é uma questão... digamos assim... a discriminação é mais gritante. Isso aí que tem que resolver. Mas tem um tipo, um grau de discriminação que vem sem discussão. Você tem que contornar, superar e encarar todos os dias, mas é uma questão muito pessoal. Não tem muito como se resolver em grupo". (Ent5/M)

Constata-se, nas falas, que a herança da democracia racial ainda permeia as concepções, reforçando a incapacidade de definição racial. Seja complexa, irrelevante, ou mesmo relevante, a subjetividade de 
quem identifica é um fator constante, enquanto o reconhecimento deste atributo, quando chamado à sua "cientificidade", ainda se encontra intimamente ligado aos marcadores antropológicos.

Todos os impasses no processo de definição do atributo estudado parecem levar a um só caminho: identificar todos os indivíduos como pardos.

Os entrevistados reduzem a dificuldade a uma solução simples que, justificada pela polissemia existente em relação aos termos, como já descrito por Figueroa (2004), autorizaria os legistas a procederem à identificação, eximindo-os de maior precisão.

Entende-se que está latente, fechada à crítica e à reflexão, a crença da existência de uma raça brasileira, exemplificada na categoria "moreno", avessa à polaridade negro/branco. Seja moreno, pardo ou faioderma, a categoria não branco é referida como uma solução para todas as dúvidas. Trata-se da promessa de trânsito referida anteriormente, por uma estratégica indefinição de fronteiras:

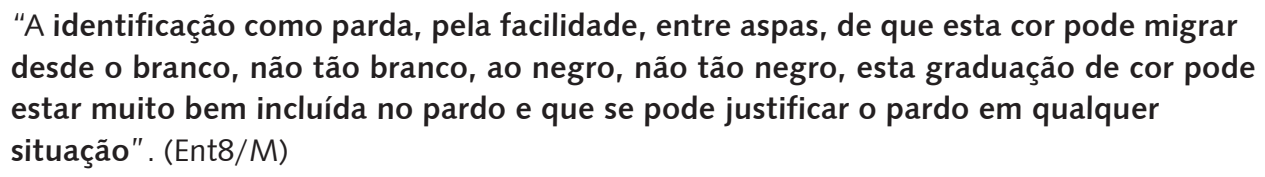

Dada esta indefinição, será possível, ao profissional, despir-se da responsabilidade legalmente investida de identificar. Livrar-se da possibilidade de erro, da possibilidade de ser questionado. Nesse sentido, a gradação da cor da pele e a impossibilidade de demarcação de uma "fronteira" inquestionável entre os extremos são utilizadas como argumento para justificar a discriminação racial, que se oculta como "in-discriminação" da cor.

A miscigenação não eliminou a discriminação, apenas a pluralizou, matizou, modalizou, conforme a presença ou ausência gradual de características "negras", mas, principalmente, pela tonalidade da cor da pele [...]. A cor da pele apresenta-se como variação intensiva do gradiente de cor (mais ou menos escuro) que desestabiliza a variável "raça" (branco, negro, não branco...). (Sales Júnior, 2006, p.233)

Este fato revela a diferença que se faz injustiça. "Serem todos brasileiros" é uma realidade que dilui e invisibiliza o efetivo limiar que é não ser branco. Ratificam-se, aí, o valor, a necessidade do pertencimento e da construção da identidade negra com base no reconhecimento da diferença. Ser negro não é a mesma coisa que ser pardo, ou preto, ou moreno, ou não branco. Ser negro é uma realidade de opressão que identifica tanto pardos quanto pretos, mesmo os que possuam ancestralidade indígena; isto não importa, pois o marcador é o "não ser" branco e, por este motivo, "não ter", na prática, os mesmos direitos.

Talvez a ideia de "inutilidade" ou "formalidade" concedida a um atributo tão crucial para a "identidade" do sujeito morto violentamente faça com que muitos médicos "resistam" a este procedimento, quer sob a forma de "esquecimento", quer sob a delegação da ação para outro profissional; ou, ainda, sob a forma de uma negação passiva, ou o que se poderia chamar de "borramento", que corresponde ao ato de marcar indiscriminadamente "qualquer alternativa" ou "sempre a mesma alternativa", que é o pardo:

\footnotetext{
"Não tem muito problema. Eu coloco quase todo mundo como faioderma. Às vezes, vem dito como melanoderma, mas é muito difícil você ver um indivíduo realmente melonoderma aqui. A grande maioria é faioderma. É difícil o indivíduo de cor negra. Quando eu tive nos Estados Unidos, você vê um cara que é claramente negro. Aqui você não vê isso com facilidade". (Ent5/M)
}

Talvez seja importante entender também que o pardo é um termo muito pouco utilizado pela população que se encontra no espaço intermediário do continuum branco-preto, para se referir a si mesma, encontrando sinonímia com outras denominações como "moreno", "mulato", "escuro"; e não 
guarda relação com nenhum grupo social existente, nenhuma etnia, e nem ao menos é nome de cor (nem ausência de cor).

É possível ainda que a "desvalorização" da raça/cor não seja referente só ao atributo, mas ao tributado: o sujeito negro. E se chegue ao absurdo de dizer que a presença de negros no IMLNR é uma raridade, pois a maioria da população é "faioderma" ou "parda".

É desse modo que a evidência (o que todo mundo pode ver) - que os negros, sejam pardos ou pretos, morrem mais - se transforma no contrário (não existem negros no IMLNR, logo, os negros não morrem de morte violenta na Bahia). Ou, quem sabe, nem existam negros no Brasil. Porque, se existem, nem a "ciência" dos médicos pode "ver". Fica mais fácil entender agora por que a "dificuldade" devida a uma pretensa complexidade transforma-se em omissão.

Identifica-se, em alguns casos, a inaceitabilidade do termo "raça" e suas implicações. Implicações que retomam, dentre outras questões, o racismo como prática atuante, presente, ainda que silenciosa, nas ações e na técnica (saber médico), independentemente da aceitabilidade ou não do termo raça, dado que raça é uma categoria social (Munanga, 1996) e a exclusão uma realidade, esta sim, inaceitável.

Como reflexo de uma realidade mais ampla, este espaço revela as diversas formas de violência a que estão relegados os negros em outros lugares. A invisibilidade é uma das mais hediondas formas de violência que, por sua vez, leva à sua naturalização. Não é visto, não existe, logo, não é importante.

Morrer muito, morrer de forma violenta. Morrer mais de forma violenta por ser parte de um grupo (ainda que muitos não possam se reconhecer nele) marginalizado do processo decisório, alienado dos seus direitos. Estar invisível para o reconhecimento de sua cidadania, de sua identidade, de sua existência. Não existir para o gozo em vida, mas para ser marcado na maca fria da morte. Morrer violentamente, por ser "percebido" de forma violenta - seja por omissão ou negligência dos espaços institucionais.

É a retroalimentação do ciclo que naturaliza a violência que vitimiza negras e negros e os segrega tanto na vida como na morte. Morre um, cinco, morrem muitos. São chacinas, mas isto já não chama mais a atenção, pois ficam segregadas nas páginas policiais ou nos programas de TV onde a miséria e a degradação humana são show, não matérias de debate social sério.

\section{Considerações finais}

Identificar o indivíduo envolve o trato com informações preciosas a respeito de como nascem, crescem, vivem e morrem. Estas informações estão intimamente ligadas à identidade racial. Entende-se que este é um dos aspectos da identidade do indivíduo e se faz, subjetivamente, em razão de o sujeito ter consciência de si mesmo e, objetivamente, por ser ele reconhecido no ambiente pelo outro. Reside aí a verdadeira identidade racial que não desarticula o indivíduo de sua realidade e, por isso, deve ser desvendada. A relação estabelecida entre a raça/cor da pele negra com a morte, a violência e a marginalidade exercem importante influência no processo de determinação da raça ou cor da pele na DO, de tal forma que, diante da naturalização deste fato, a identificação passa a ter pouco valor.

Realidade tão luminosa que cega. Os negros morrem mais, de forma indigna, se matam e são mortos em proporções inusitadas. Isto não causa nenhuma estranheza aos profissionais e à instituição. A morte dos brancos que chegam ao IMLNR está relacionada a uma circunstância pontual, sem implicações judiciais. Ao passo que o homicídio, de fato ou presumido, traz a marca da violência marginal, relacionada com drogas, crime, ilegalidade, com aquilo que inscreve o corpo morto em um horizonte de culpabilidade, quase que justificando a morte violenta e, consequentemente, a rejeição social e a discriminação.

A morte violenta tem cor. Mesmo que a maioria dos profissionais de saúde reconheça a importância da raça/cor da pele na instituição estudada, isto nem sempre ocorre na prática. Diante deste quadro, a prática do médico legista constitui-se pelo predomínio de duas ações: a primeira, pela omissão; a segunda, consequência da primeira, pela imprecisão. Nem atende inteiramente à dimensão política de permitir, aos familiares do morto, que forneçam sua identidade com base na experiência social, nem é 
fruto de qualquer observação neutra e objetiva que o racionalismo empiricista preconiza para a constituição de um saber científico. Estas ações de omissão e ambiguidade só podem produzir distorções, apontando para estatísticas de raça/cor da pele não confiáveis. Já se sabe de antemão como são produzidas. Nada a ver com o sujeito morto, nem suas qualidades, mas com o processo social que engendra a prática profissional.

Enquanto processo histórico, a ideologia do "branqueamento" foi construída com base na ideia de "superioridade branca", substituta, no Brasil, da ideia anglo-europeia de supremacia branca, e que se encontrava na base da crença de que a miscigenação "embranqueceria" o Brasil. Essa ideia se atualiza, ainda neste século, por ações cotidianas que assimilam os significantes valorizados pela elite branca e sua dinâmica racista (Bento, 2002), e repercutem no reconhecimento da identidade negra.

As informações a respeito da raça/cor da pele das vítimas de morte violenta enviesam as informações sobre a mortalidade da população negra. Ora, se esta é a base de dados proposta para fundamentar diagnósticos da situação de saúde que orientam as políticas públicas, o sistema gera um problema, e não uma solução.

Cria-se uma "névoa" informacional conveniente, ou melhor, conivente com a ausência de estratégias específicas de combate à violência neste grupo, revelando a ineficácia do Estado. Percebe-se que, para a construção de uma prática que possa transformar este processo negativamente racializado, faz-se necessária a incorporação de novos saberes e práticas, que tornem conscientes os sujeitos envolvidos na geração de informações coerentes com sua relevância social.

Quer estes sujeitos sejam gestores, militantes de movimentos sociais ou profissionais, uma sensibilização que exponha esta ferida seria um primeiro passo a ser dado. Por meio de sujeitos mais sensíveis à vulnerabilidade que a identidade sociorracial confere, será possível, à sociedade, adquirir nova compreensão da raça/cor da pele, dando a este constructo social sentidos mais humanos e verdadeiros.

\section{Colaboradores}

Andreia Beatriz Silva dos Santos foi responsável pela elaboração do projeto, coleta de dados, análise e redação do artigo. Thereza Christina Bahia Coelho trabalhou na elaboração do projeto, análise dos dados e redação do texto; e Edna Maria Araújo contribuiu na análise dos dados e redação do manuscrito.

\section{Referências}

ARAÚJO, E.M. et al. Diferenciais de raça/cor da pele em anos potenciais de vida perdidos por causas externas. Rev. Saude Publica, v.43, n.3, p.405-12, 2009.

AZEVEDO, E. Raça: conceito e preconceito. 2.ed. São Paulo: Ática, 1990.

BARBOSA, M.I. Racismo e saúde. 1998. Tese (Doutorado) - Faculdade de Saúde Pública, Universidade de São Paulo, São Paulo. 1998.

BATISTA, L.E. Masculinidade, raça-cor e saúde. Cienc. Saude Colet., v.10, n.1, p.71-80, 2005.

BENTO, M.P.S. Branqueamento e branquitude no Brasil. In: CARONE, I.; BENTO, M.P.S. (Orgs.). Psicologia social do racismo: estudos sobre branquitude e branqueamento no Brasil. Petrópolis: Vozes, 2002. p.25-58.

BRASIL. Ministério da Saúde. Fundação Nacional de Saúde. Manual de instruções para o preenchimento da declaração de óbito. 3.ed. Brasília: FNS, 2001. 
IDENTIFICAÇÃO RACIAL E A PRODUÇÃO DA INFORMAÇÃO ...

CARDOSO, A.M.; SANTOS, R.V.; COIMBRA JÚNIOR, C.E.A. Mortalidade infantil segundo raça-cor no Brasil: o que dizem os sistemas de informação. Cad. Saude Publica, v.21, n.5, p.1602-8, 2005.

CASHMORE, E. Dicionário de relações étnicas e raciais. Trad. Dinah Kleve. São Paulo: Sumus, 2000.

CHOR, D.; LIMA, C.R.A. Aspectos epidemiológicos das desigualdades raciais em saúde no Brasil. Cad. Saude Publica, v.21, n.5, p.1586-94, 2005.

DEVER, G.E. A epidemiologia na administração dos serviços de saúde. São Paulo: Pioneira, 1988

FERREIRA, A.B.H. Mini Aurélio: o minidicionário da língua portuguesa. Curitiba: Positivo, 2006.

FIGUEROA, A. Contextualização conceitual e histórica. In: SEMINÁRIO NACIONAL DE SAÚDE DA POPULAÇÃO NEGRA, 2004, Brasília. Caderno de textos básicos... Brasília: Seppir, Ministério da Saúde, 2004. p.11-45.

INSTITUTO BRASILEIRO DE GEOGRAFIA E ESTATÍSTICA - IBGE. Séries Estatísticas \& Séries Históricas. Pesquisa Nacional por Amostra de Domicílio 2001-2009. Rio de Janeiro, 2012. Disponível em: <http://seriesestatisticas.ibge.gov.br/ series.aspx?vcodigo $=$ PD336\&sv $=32 \& t=$ populacao-residente-cor-raca $>$. Acesso em: 16 nov. 2012.

LOPES, F. Para além da barreira dos números: desigualdades raciais e saúde. Cad. Saude Publica, v.21, n.5, p.1595-601, 2005.

MINAYO, M.C.S. O desafio do conhecimento: pesquisa qualitativa em saúde. 6.ed. São Paulo: Hucitec, 1999.

MUNANGA, K. Identidade, cidadania e democracia: algumas reflexões sobre os discursos anti-racistas no Brasil. RESGATE - Rev. Interdisc. Cultura, n.6, p.17-24, 1996. Disponível em: <http://www.cmu.unicamp.br/seer/index.php/resgate/article/ view/72/77>. Acesso em: 16 abr. 2013

NASCIMENTO, A. Brazil: mixture or massacre?: essays in the genocide of a Black people. Trad. Elisa Larkin Nascimento. Dover: The Majority Press, 1989.

OSÓRIO, R.G. O sistema classificatório de raça cor ou raça do IBGE. Brasília: IPEA, 2003. (Textos para Discussão, n.996).

PRANDI, R. De africano a afro-brasileiro: etnia, identidade, religião. Rev. USP, n.46, p.52-65, 2000. Disponível em: <http://www.usp.br/revistausp/46/04reginaldo.pdf >. Acesso em: 16 abr. 2013.

RAMOS, J.S. Ciência e racismo: uma leitura crítica em raça e assimilação em Oliveira Viana. Hist., Cienc., Saúde - Manguinhos, v.10, n.2, p.573-601, 2003.

REIS, J.J. Rebelião escrava no Brasil: a história do levante dos malês em 1835. São Paulo: Companhia das Letras, 2003

SALES JÚNIOR, R. Democracia racial: o não dito racista. Tempo social - Rev. Sociol. USP, v.18, n.2, p.229-58, 2006.

SANTOS, A. Morte por causas externas: um estudo sobre a identificação da raça/cor da pele no Instituto Médico Legal de Salvador/Bahia.2008. Dissertação (Mestrado) Programa de Pós-Graduação em Saúde Coletiva, Departamento de Saúde, Universidade Estadual de Feira de Santana, Feira de Santana. 2008. 
SILVA, S.A. Who is black in Brazil? A timely or a false question in Brazilian race relations in the era of affirmative action? Latin Am. Perspect., v.33, n.4, p.30-48, 2006.

TELLES, E.E. Incorporating race and ethinicity into the UN millennium development goals. Inter-Am. Dial. - Race Report, p.1-5, 2007. Disponível em: <http:// www.thedialogue.org/PublicationFiles/telles.pdf>. Acesso em: 15 nov. 2012.

VOLOCHKO, A. Mortalidade evitável na região sul do Brasil, 2000: desigualdades raciais e sexuais. 2005. Tese (Doutorado) - Secretaria da Saúde de São Paulo, Programa de Pós-Graduação em Ciências, São Paulo. 2005.

SANTOS, A.B.S.; COELHO, T.C.B.; ARAÚJO, E.M. Identidad racial y la producción de información en salud. Interface (Botucatu), v.17, n.45, p.341-55, abr./jun. 2013.

Ese estudio examina la producción de información sobre raza/color de la piel de los cadáveres sometidos a autopsia en el Instituto de Medicina Legal (IML) de Salvador/ Bahia en 2007. Los datos se obtuvieron por medio de entrevistas con médicos legistas, ayudantes de autopsia y con el personal de la División de Entrega de Cadáveres, en la observación y en fuentes documentales. El análisis reveló que el proceso de identificación de la raza/color de la piel se omite, es impreciso y distorsiona las informaciones finales que constan en los Certificados de Defunción. Hubo una clasificación difusa de negros y mestizos como faiodermas, generando una "niebla" en la información, mientras que la muerte de los blancos fue "accidental". El asesinato lleva la marca de la violencia marginal, relacionada con drogas y crimen y con todo lo que inscribe al muerto en un horizonte de culpa, casi justificando la muerte violenta y la discriminación.

Palabras clave: Identificación racial. Sistema de Información sobre Mortalidad (SIM). Racismo. Raza/color. 
